Bond University

Research Repository

\title{
Parental bonding, adult attachment, and theory of mind: A developmental model of alexithymia and alcohol-related risk
}

Lyvers, Michael; Mayer, Kaitlin; Needham, Katarina; Thorberg, Fred Arne

Published in:

Journal of Clinical Psychology

DOI:

10.1002/jclp.22772

Licence:

Other

Link to output in Bond University research repository.

Recommended citation(APA):

Lyvers, M., Mayer, K., Needham, K., \& Thorberg, F. A. (2019). Parental bonding, adult attachment, and theory of mind: A developmental model of alexithymia and alcohol-related risk. Journal of Clinical Psychology, 75(7), 1288-1304. https://doi.org/10.1002/jclp.22772

\section{General rights}

Copyright and moral rights for the publications made accessible in the public portal are retained by the authors and/or other copyright owners and it is a condition of accessing publications that users recognise and abide by the legal requirements associated with these rights.

For more information, or if you believe that this document breaches copyright, please contact the Bond University research repository coordinator 
Parental Bonding, Adult Attachment, and Theory of Mind: A Developmental Model of Alexithymia and Alcohol-Related Risk

${ }^{1}$ Michael Lyvers, Ph.D.

${ }^{1}$ Kaitlin Mayer, Graduate Diploma of Psychological Science

${ }^{1}$ Katarina Needham, Bachelor of Psychological Science (Honours)

${ }^{2}$ Fred Arne Thorberg, Ph.D.

${ }^{1}$ Bond University

Gold Coast, Qld Australia

${ }^{2}$ Innlandet Hospital Trust

Brumunddal, Norway 


\begin{abstract}
Objectives. A developmental model of alexithymia in relation to alcohol-related risk was examined. Method. Validated indices of parental bonding, adult attachment, alexithymia, theory of mind, alcohol-related risk and mood were administered to a nonclinical sample of 286 alcohol using men and women. Results. Hierarchical regression incorporating demographic and psychosocial variables accounted for $44 \%$ of variance in alexithymia. Modelling indicated a significant path from dysfunctional maternal bonding to insecure adult attachment to alexithymia to risky drinking; a separate path indicated an indirect effect of alexithymia in the association between deficient theory of mind and risky drinking. Conclusions. Findings were consistent with a developmental model where dysfunctional parental bonding in childhood manifests in adulthood as insecure attachment and alexithymia, the latter reflecting insufficient acquisition of emotion regulation skills; alexithymia in turn increases the risk of problematic drinking as an emotion regulation strategy.
\end{abstract}

Keywords: emotion regulation, alexithymia, alcohol abuse, theory of mind 
Over the past decade, there has been increased research interest in the subclinical personality trait alexithymia, particularly regarding its association with risky or harmful alcohol use in both clinical and nonclinical samples (Bruce, Curren, \& Williams, 2012; Cruise \& Becerra, 2018; Thorberg, Young, Sullivan, \& Lyvers, 2009). Alexithymia is a multidimensional personality construct defined by difficulties identifying and describing feelings and a concrete or externally oriented thinking style (Taylor \& Bagby, 2000). Deficient ability to recognize the relationship between certain emotions (e.g., anxiety) and physical arousal (e.g., nausea, “butterflies”) may hinder insight into the origin of somatic symptoms, leading to maladaptive emotional self-regulation strategies among individuals with high levels of alexithymia (Beadle, Paradiso, Salerno, \& McCormick, 2013). Such deficits in self-regulation likely contribute to the heightened prevalence of alexithymia among those who drink at risky levels in the general population as well as among those diagnosed with alcohol use disorder (AUD; Bruce et al., 2012; Cruise \& Becerra, 2018).

\section{Alexithymia in Relation to Parental Bonding, Adult Attachment and Alcohol Use}

Little is known about the etiology of alexithymia. The heritability of alexithymia has been estimated at only 30-33\% (Jorgensen, Zachariae, Skytthe, \& Kyvik, 2007), suggesting that there are substantial developmental influences on the expression of this trait in the population. A plausible childhood source of such influences is primary caregiver bonding experiences, which have been proposed to play an important role in alexithymia (Montebarocci, Codispoti, Baldaro, \& Rossi, 2004; Thorberg, Young, Sullivan, \& Lyvers, 2011). Inadequate parental bonding during infancy and childhood is theorized to result in deficits of self-regulation, emotion recognition and interpersonal attachment security (note that in the present context "bonding” is used in reference to the early parent-child relationship, whereas "attachment” is used more broadly to include adult relationships). The deficient capacity to identify and express emotions, in concordance with insecure adult 
attachment, may encourage reliance on substances such as alcohol instead of social support for coping with stress, as well as for mood effects such as emotional disinhibition and/or alleviation of negative affect (Thorberg et al., 2016a). Deficient interoceptive awareness associated with high alexithymia (Brewer, Cook, \& Bird, 2016) may mean there is limited recognition of internal cues of overconsumption, further promoting risky or harmful levels of drinking.

Reports of insecure attachment styles in those diagnosed with AUD have suggested to some authors that insecure attachment often plays an important etiological role (De Rick, Vanheule, \& Verhaeghe, 2009; Flores, 2004; Thorberg \& Lyvers, 2006). Insecure (especially anxious) attachment, as well as fear of intimacy, is also characteristic of those who score highly on indices of alexithymia (Lyvers, Davis, Edwards, \& Thorberg, 2017; Thorberg, Young, Sullivan, Lyvers et al., 2011a). In addition, the perception of one’s past relationship/s with one or more primary caregivers as having been dysfunctional (i.e., low parental care and/or high parental overprotection) is also prevalent among those with high alexithymia (Thorberg, Young, Sullivan, \& Lyvers, 2011). The concept of attachment disorders stems from Attachment Theory (Bowlby, 1958), a psychological model that describes dynamics of both short- and long-term reciprocal relationships. In adulthood, anxious attachment styles are characterized by a desire to be close, but ineffectively seeking such positive interaction due to hypervigilance of negative emotions and insecurity (Collins, 1996). Alexithymia and anxious attachment are both associated with interpersonal difficulties (Spitzer, Siebel-Jurges, Barnow, Grabe, \& Freyberger, 2005; Vanheule, Desmet, Meganck, \& Bogaerts, 2007), and attachment styles have been shown to have a moderating influence on the link between alexithymia and relationship problems (Montebarocci et al., 2014).

Evidence suggests that adult attachment styles are likely to reflect influences of functional or dysfunctional parental bonding experiences in childhood. For example, a meta- 
analysis across eight studies indicated that the insecure attachment style expressed by highly alexithymic individuals was related to their perceptions of dysfunctional parental (primarily maternal) bonding (Thorberg, Young, Sullivan \& Lyvers, 2011). Functional parental bonding is said to occur when parent-child relationships enable development of a secure attachment style by providing a warm, intimate, and continuous relationship with at least one primary caregiver, most commonly the mother (Bowlby \& King, 2004). The absence of a functional bond with the primary caregiver during childhood may lead to an insecure attachment style through prolonged and consistent deprivation of appropriate care and empathy towards the child, and/or persistent and restrictive overprotection (Zafiropoulou, Avagianou, \& Vassiliadou, 2014). Functional parental bonding does involve protection; however, the fundamental aspect of overprotection is its intrusiveness accompanied by a lack of understanding of the child or adolescent's autonomous needs (Asano et al., 2013).

\section{Self-Regulation and Theory of Mind}

Parental bonding experiences are thought to have a profound influence on selfregulation, as the primary caregiver can facilitate the acquisition of appropriate physiological, emotional and behavioral self-regulatory strategies and abilities for the child (de Cock et al., 2017; Moore et al., 2009; Sprangler, Fremmer-Bombik, \& Grossmann, 1996). The capability and motivation to self-regulate require knowledge of both norms and expectations within relationships, and an understanding of interpersonal consequences of actions (Baldwin, Carrell, \& Lopez, 1990; Higgins, Klein, \& Strauman, 1985, 1987). Starting in infancy, functional parental bonding facilitates the development of self-regulation as parents and infants engage in reciprocal actions during close contact to maintain optimal levels of arousal and engagement (Tronick, 2007). Development of self-regulation appears to be concomitant with acquisition of an ability to understand and predict the behaviors and emotions of others, often referred to as Theory of Mind (ToM; Lane, Hsu, Locke, Ritenbaugh, \& Stonnington, 
2015). Post-institutionalized children who had experienced minimal caregiver bonding have reportedly shown deficient or delayed cognitive development, including ToM deficits (Nelson et al., 2007). Alternatively, acquisition of self-regulatory skills may normally occur in parallel to the development of ToM, as recent evidence points to language acquisition as a crucial factor allowing for the understanding of others' perspectives, behaviors and motives (Miller, 2006; Milligan, Astington, \& Dack, 2007).

A recent study (Lyvers, Kohlsdorf, Edwards, \& Thorberg, 2017) examined ToM among university students - a group “naturally” preselected for relatively high level linguistic ability - in relation to emotional self-regulation, negative moods and alexithymia. Poor emotional self-regulation, as indexed by mood regulation expectancies, mediated the relationship between alexithymia and negative moods. Further, in a hierarchical regression model the externally-oriented thinking facet of alexithymia predicted lower scores on an index of ToM that was also used in the current study. A recent meta-analysis supported a strong negative association between AUD and ToM (Onuoha, Quintana, Lyvers, \& Guastella, 2016), consistent with the notion that impaired understanding of others' intentions and emotions can heighten an individual's susceptibility to rely on alcohol use as a coping mechanism rather than seeking social support, thereby increasing alcohol-related risk (Kuntsche, Knibbe, Gmel \& Engels, 2005). Thus, in the present study the association between deficient ToM and risky or problematic drinking was predicted to show an indirect effect of alexithymia in a nonclinical sample. A more tentative hypothesis was that dysfunctional maternal bonding experiences in childhood would manifest as deficient ToM in adulthood. This prediction was necessarily tentative given the aforementioned evidence that language development is crucial to development of ToM, perhaps even irrespective of parental bonding experiences. 


\section{The Current Study}

Previous studies have examined ToM or alexithymia in relation to drinking and other variables in clinical AUD samples (Onuoha et al., 2016; Thorberg et al., 2010, 2011a, 2011b), or examined parental bonding and adult attachment in relation to alexithymia in patients diagnosed with attention deficit or somatoform disorders (Edel et al., 2015; Gil, Scheidt, Hoeger \& Nickel, 2009). Additional studies have examined relationships between parental bonding or adult attachment and alexithymia in nonclinical samples (Taylor, Bagby, Kushner, Benoit, \& Atkinson, 2014; Thorberg, Young, Sullivan, \& Lyvers, 2011), and one recent study assessed relationships between alexithymia, drinking and ToM in a nonclinical sample (Lyvers, Kohlsdorf et al., 2018). The present study sought to incorporate the reported outcomes of these disparate strains of research and theory into a single model, based on Attachment Theory, that might plausibly account for alexithymia as a trait and its association with alcohol-related risk. The association of alexithymia with deficient ToM was examined from within this framework as well. The current study thus assessed whether parental bonding, adult attachment security, and ToM would predict alexithymia and alcohol-related risk (operationally defined by scores on the Alcohol Use Disorders Identification Test, or AUDIT; Babor, Higgins-Biddle, Saunders, \& Monteiro, 2001) in a nonclinical alcohol-using sample in line with the model depicted in Figure 1. Dysfunctional parental (primarily maternal) bonding, insecure adult attachment, and deficient ToM were all expected to show positive relationships with alexithymia and to account for a substantial amount of variance in alexithymia in a hierarchical regression model. As alexithymia has been previously reported to vary in some studies according to demographic factors of age (Lane, Sechrest, \& Riedel, 1998; Mattila, Salimen, Nummi, \& Joukamaa, 2006), gender (Levant, Hall, Williams, \& Hasan, 2009), and education (Lennartsson, Horwitz, Theorell, \& Ullen, 2017; Pasini, Chiaie, Seripa, \& Ciani, 1992), such factors were controlled in the regression model. Negative moods 
such as depression, anxiety and stress are common correlates of alexithymia (e.g., Lyvers, Kohlsdorf et al., 2017) and thus their potential influences on current responding were also controlled. Secondly, path analysis was conducted to examine the hypothesis that dysfunctional parental (primarily maternal) bonding in childhood is associated with insecure attachment and deficient ToM in adulthood, which in turn are associated with deficits in the ability to recognize and self-regulate one's own feelings (alexithymia) due to the paucity of close interpersonal relationships necessary to acquire such skills during childhood (and beyond). Further, the model posited - based on previous evidence cited earlier - that alexithymia increases the likelihood of using alcohol to regulate mood and/or to aid in the experiencing of emotional feelings via disinhibition, which in turn, combined with poor interoceptive awareness in those with high levels of alexithymia, increases the risk of drinking at risky or harmful levels. The present study was not intended to address issues of temporal sequencing or causation, which would require the support of longitudinal data; rather the goal was to establish whether the proposed associations among variables in the model would be present in a nonclinical sample. The model is illustrated in Figure 1.

\section{Method}

\section{Participants}

There were 291 participants recruited for the study (61.1\% females) aged between 18 and 62 years $(M=26$ years, $S D=9)$. Participants were recruited from two Australian universities (30\%) and Facebook (70\%) via notices requesting participants aged 18 and older, who consume alcohol at least occasionally, to participate in a research investigation of personality, social behaviors and drinking. Non-drinkers and people under the age of 18 were ineligible and thus excluded. The incentives of either partial credit towards an undergraduate psychology subject (19\%) or the chance to win a random draw for a $\$ 50$ gift voucher (81\%) were offered. The majority of respondents stated their country of origin as Australia (67\%), 
followed by the United States (6\%), United Kingdom (5\%), New Zealand (4\%), and South Africa (2\%). The remaining 16\% were classified as "other" as there were fewer than two people from their country of origin or they did not report their country of origin. Five cases were identified as multivariate outliers via Mahalanobis distance $(p<.001)$ and were removed, resulting in a final sample of 286.

\section{Materials}

The following questionnaires were completed online via the survey hosting website Qualtrics.com.

Demographic questionnaire. Participants were administered an 11-item questionnaire assessing their age, gender, country of origin, education, study, substance use history, and current medications.

Parental Bonding Instrument (PBI; Parker, Tupling, \& Brown, 1979). The PBI is a self-report measure of parental care and overprotection that asks the participant to retrospectively report from their first 16 years of life. There are two separate 25-item scales: one measures maternal bonding and the other measures paternal bonding. Items are scored using a four-point Likert scale ranging from 0 (Very like) to 3 (Very unlike). To increase parsimony in the model the Maternal Care scale was reversed and combined with the Maternal Overprotection scale, forming a single continuous variable: Maternal Dysfunction. The same process was undertaken for the paternal scales of the PBI. Cronbach alpha reliability in the present study was $\alpha=.71$ for Maternal Dysfunction and $\alpha=.75$ for Paternal Dysfunction. The global Cronbach was $\alpha=.93$.

Revised Adult Attachment Scale (RAAS; Collins \& Reed, 1990). The RAAS is an 18-item self-report scale designed to measure individual differences of adult attachment patterns in relationships. It consists of three continuous subscales of six items each: Close, Depend, and Anxiety. Items are scored on a five-point Likert scale ranging from 1 (Not at all 
characteristic of me) to 5 (Very characteristic of me), and the average is then calculated for each subscale. In the present study the variable Secure Attachment was operationalized by combining Close and Depend scores with reversed Anxiety scores. A continuous scale was chosen as opposed to using categorical cut-offs, as current literature suggests that attachment styles are better conceptualized as dimensional (e.g., Fraley, Hudson, Heffernan, \& Segal, 2015). Cronbach alpha reliability for the RAAS in the current study was $\alpha=.80$ for Close, $\alpha$ $=.82$ for Depend, and $\alpha=.92$ for Anxiety.

\section{Reading the Mind in the Eyes Test, Revised Adult (RMET; Baron-Cohen,}

Wheelwright, Hill, Raste, \& Plumb, 2001). The RMET is designed to measure Theory of Mind (ToM) by testing participants' level of accuracy when inferring the emotional states of others from photographs of eye gaze. There are 36 photographs presented, each with four emotional descriptors to choose from in selecting the state that corresponded to the image. For every correct answer, the participant is given one point, and the sum of the points yields scores ranging from 0 to 36 with lower scores indicating poorer ToM. Cronbach alpha reliability for the RMET in the present study was $\alpha=.84$.

Toronto Alexithymia Scale (TAS-20; Bagby, Parker, \& Taylor, 1994). The TAS20 is a 20-item self-report scale designed to measure alexithymia. Items are scored on a fivepoint Likert scale ranging from 1 (Strongly disagree) to 5 (Strongly agree). There are three subscales reflecting three facets of alexithymia, difficulty identifying feelings (DIF), difficulty describing feelings (DDF) and externally oriented thinking (EOT), as well as an overall total alexithymia score. The present study used the total scores as a continuous measure ranging from 20 to 100, but TAS-20 scores can also be used to classify people as highly alexithymic (61+), borderline high alexithymic (52 - 60) or having low or no alexithymia (<52; Bagby, Taylor \& Parker, 1994). In the current sample the Cronbach alpha reliability index for the TAS-20 was $\alpha=.88$. 
Alcohol Use Disorders Identification Test (AUDIT; Babor et al., 2001). The

AUDIT is a 10-item screening tool designed to assess alcohol-related risk or harm. Items assess three factors: alcohol consumption, measured by three items (e.g., "How often do you have a drink containing alcohol?”); alcohol dependence, measured by three items (e.g., “How often during the last year have you found that you were not able to stop drinking once you had started?”); and alcohol-related problems, measured by four items (e.g., “Have you or someone else been injured because of your drinking?”). Items 1 to 8 are measured on a fivepoint Likert scale ranging from 0 (Never) to 5 (Daily or Almost Daily), whereas items 9 and 10 are weighted on a three-point Likert Scale of 0 (No), 2 (Yes, but not in the last year), and 4 (Yes, during the last year). The AUDIT total score can range from 0 to 40 . In the current study, the Cronbach alpha reliability index for the AUDIT was $\alpha=.82$.

\section{Depression Anxiety Stress Scales-21 (DASS-21; Lovibond \& Lovibond, 1995).}

The DASS-21 is a self-report measure used to assess negative affective states experienced over the past week. It contains 21 items assessing three factors of depression, anxiety, and stress, with seven items per factor scored on a Likert scale from 0 (Did not apply to me at all) to 3 (Applied to me very much, or most of the time). The total score was used in the present study to control for potential influences of negative mood on the variables of interest. In the current sample, the Cronbach alpha reliability index for the total DASS-21 was $\alpha=.95$.

\section{Procedure}

Ethics approval was granted by the human research ethics committees of two universities prior to data collection. Participants accessed the Qualtrics online survey link via email or Facebook, and were asked to select "yes" or "no" to consent to their anonymous data being used within the project (three participants who ticked “no” were not included in the total sample of 286 participants despite completing the study). Participants were informed about the research project on the first page of the Qualtrics online survey, including contact 
details of all researchers involved, a layperson description of the research, information about incentives, and acknowledgement of potential risks such as psychological distress due to the confronting nature of some scale items. Order of questionnaires was uniquely randomized per participant. Responses were collected over a five-month period. An emailed screenshot of the final page of the online survey was required to be eligible for the incentive.

\section{Results}

Hierarchical regression was conducted using SPSS 24, and path analysis was conducted using Analysis of a Moment Structures (AMOS). Missing data was below five percent. To deal with missing data, an expectation maximization algorithm was used. A priori $\mathrm{G}^{*}$ Power analysis indicated that with an alpha of .05 and power level of .95 , a sample size of 178 participants was necessary to detect a medium effect size of .15 in the hierarchical regression (Faul, Erdfelder, Buchner, \& Lang, 2009). A minimum sample size of 200 participants is suggested for the path modelling methodology used in the present study (Blunch, 2008; Mueller, 1996; Schumacker \& Marcoulides, 1998). The final sample of 286 met these requirements. The sequencing of the model was theoretically based on the conceptual model described earlier. The path model was expected to be just-identified or over-identified, by portraying degrees of freedom greater than zero.

\section{Preliminary Statistics}

Of the final sample of 286 participants, 55 (19\%) were identified as highly alexithymic by TAS-20 cut-off score (Bagby, Taylor et al., 1994). Descriptive statistics for study variables are provided in Table 1. Pearson's bivariate correlations were calculated for all continuous measures and are presented in Table 2. TAS-20 alexithymia scores were significantly positively correlated with AUDIT risky drinking scores, PBI Overprotect subscales, Maternal and Paternal Dysfunction, the 
Anxiety scale of the RAAS, and the total DASS-21 negative mood index, and were significantly negatively correlated with the PBI Care subscales, RAAS Close and Depend, and RMET scores. All facets of PBI and RAAS were significantly correlated in expected directions. Care was positively correlated with Close and Depend, and negatively correlated with Anxiety. Overprotect was positively correlated with Anxiety, and negatively correlated with Close and Depend. RMET performance was negatively correlated with AUDIT, TAS-20, and Paternal Overprotect, but showed no relationship with the attachment dimensions.

\section{Predictors of Alexithymia}

A five-step hierarchical regression was conducted based on TAS-20 alexithymia scores to assess whether the variables in the proposed model could account for variance in alexithymia in the manner expected. Order of entry of predictors was based on evidence and theory described earlier. Coefficients are displayed in Table 3. At step one, demographic control variables of age, gender and education were entered as these factors were reportedly associated with alexithymia in some of the previous research cited earlier; they accounted for $2.7 \%$ of variance in TAS-20 alexithymia scores, and the model was non-significant, $F(3,261)=2.43, p=.06$. At step two the addition of another control variable, the negative mood index of DASS-21 total scores, significantly improved prediction of alexithymia scores, $\Delta F(1,260)=101.03, p<.001$, accounting for an additional $27.2 \%$ of variance and yielding a significant model, $F(4$, $260)=27.77, p<.001$. At step three, the inclusion of maternal and paternal dysfunction indices from the PBI significantly improved prediction of alexithymia, $\Delta F(2,258)=8.28, p<.001$, accounting for an additional $4.2 \%$ of variance with the model remaining significant, $F(6,258)=22.31, p<.001$. DASS-21 and maternal dysfunction were significant predictors. At step four, addition of the ToM index, RMET 
scores, significantly contributed to the model, $\Delta F(1,257)=10.38, p<.001$, accounting for an additional $2.6 \%$ of variance with the model remaining significant, $F(7,257)=$ 21.30, $p=.001$. DASS-21 and maternal dysfunction remained significant at this step. At the final step, addition of the secure attachment index derived from RAAS scores significantly contributed to the model, $\Delta F(1,256)=34.45, p<.001$, accounting for an additional $7.5 \%$ of variance with the model remaining significant, $F(8,256)=25.37$, $p<.001$. The final model accounted for $44 \%$ of variance in alexithymia, with DASS21, maternal dysfunction, the RMET index of ToM, and the secure attachment index as significant predictors (see Table 3).

\section{Path Analysis}

Model summary. A path analysis using the measured variables was conducted to evaluate the direct and indirect relationships within the proposed developmental model of alexithymia and risky alcohol use (see Figure 1). Model construction and analyses were conducted using IBM SPSS AMOS version 24. Parameters were estimated using maximum likelihood methods. Maternal and paternal dysfunction were exogenous predictor variables expected to predict alexithymia, both directly and indirectly through the mediator variables of secure attachment and ToM. In turn, secure attachment and ToM were expected to predict risky alcohol use, both directly and indirectly through alexithymia. The overall model was found to demonstrate good fit with the data, $\chi^{2}(3)=0.94, p=.816, G F I=.99, N F I=.99, C F I$ $=1.00, R M S E<.01$. Standardized and unstandardized coefficients with associated $95 \%$ confidence intervals of all direct and indirect effects are presented in Table 4 and Table 5 respectively.

Prediction of alexithymia. Review of individual paths indicated that paternal dysfunction did not significantly predict any variable, either directly or indirectly (all pvalues $>$.06). Maternal dysfunction was found to indirectly predict alexithymia through its 
association with adult attachment style, but not ToM. Specifically, higher retrospective reports of maternal dysfunction during childhood were predictive of less secure attachment tendencies as an adult $(\beta=-.38, p=.001)$, with less secure attachment predictive of higher levels of self-reported alexithymia $(\beta=-.50, p=.001)$. A bias-corrected bootstrapped $95 \%$ confidence interval for the indirect effect based on 1000 bootstrapped samples did not contain zero $(\beta=.10$, lower $C I=.05$, upper $C I=.16)$, confirming adult attachment style as a significant mediator. When controlling for the indirect effect, maternal dysfunction did not demonstrate a significant direct effect with alexithymia $(\beta=.12, p=.06)$. Though not predicted by maternal dysfunction $(\beta=-.06, p=.30)$, ToM was a significant direct predictor of alexithymia $(\beta=-.18, p=.001)$ such that more deficient ToM was predictive of increased alexithymia.

Predictors of risky alcohol use. Analyses indicated that both adult attachment style and ToM indirectly predicted riskier alcohol use through increased alexithymia. Less secure attachment $(\beta=-.50, p=.001)$ and poorer ToM $(\beta=-.18, p=.001)$ were both uniquely associated with higher alexithymia. Higher alexithymia was subsequently predictive of riskier alcohol use, $\beta=.36, p=.001$. Bias-corrected bootstrapped 95\% confidence intervals based on 1000 bootstrapped samples confirmed alexithymia to be a significant mediator of the relationships between attachment and risky drinking $(\beta=-.18$, lower $C I=-.28$, upper $C I=-$ $.11)$ and between ToM and risky drinking $(\beta=-.07$, lower $C I=-.13$, upper $C I=-.03)$. After controlling for the influence of alexithymia, the direct effect of ToM remained significant ( $\beta$ $=-.20, p=.003)$, but the direct effect of attachment was non-significant $(\beta=.06, p=.36)$.

Refined model. A simplified model was constructed post hoc by trimming the nonsignificant paths of the original analysis (Meyers, Gamst, \& Guarino, 2017; Olobatuyi, 2006). This new model was found to be a good fit with the data, $\chi^{2}(4)=5.16, p=.27, G F I=.99$, $N F I=.98, C F I=.99, R M S E=.03$. All paths retained their direction and significance from 
the original analysis. A representation of the refined model is presented in Figure 2 with associated standardized coefficients.

\section{Discussion}

Results were largely consistent with predictions based on Attachment Theory. One exception was that although deficient ToM - as indexed by poorer performance on the RMET - was (as predicted) significantly associated with both the TAS-20 index of alexithymia and the AUDIT index of risky drinking, ToM was unrelated to perceptions of parental bonding in childhood (except for a weak negative correlation with paternal overprotection), as well as adult attachment dimensions and attachment security. On the other hand, according to the path analysis deficient ToM was linked to risky drinking both directly and indirectly through alexithymia, as predicted. Further, dysfunctional maternal bonding in childhood was linked to insecure adult attachment, which in turn was linked to risky drinking through alexithymia in the Attachment Theory-based model. In contrast to the apparent influences of maternal bonding in relation to the other variables (except ToM), the hierarchical regression model and the path analysis did not support an influence of paternal bonding on alexithymia or risky drinking, respectively, despite paternal dysfunction showing significant bivariate correlations in expected directions with the indices of alexithymia, negative mood, adult attachment and ToM.

In the final model the relationships among variables were consistent with the proposed role of dysfunctional maternal bonding experiences during childhood as retrospectively assessed via the PBI. Based on considerations derived from Attachment Theory as described earlier, inadequate bonding between mother and child was hypothesized to interfere with normal emotional development, including emotional self-regulation, which later manifests in adulthood as insecure attachment and alexithymia; the latter in turn is likely to promote use of alcohol to cope with stress and other negative states, and/or to achieve 
temporarily improved emotional self-awareness via alcohol-induced disinhibition. The absence of any evident role of paternal bonding in the final model is consistent with other work as summarized in the meta-analysis by Thorberg, Young, Sullivan and Lyvers (2011), which indicated that unlike self-reported maternal bonding experiences, self-reported paternal bonding experiences show minimal association with alexithymia in nonclinical samples. The present study's path from dysfunctional maternal (but not paternal) bonding in childhood to insecure adult attachment is consistent with the common role of the mother as the primary caregiver for the child in the majority of cases, and which - according to Attachment Theory - forms a basis for the development of secure or insecure attachment styles into adulthood (Ainsworth, 1991). This does not preclude a similar role for other caregivers, especially in the absence of the mother; rather it is simply consistent with the most common parenting pattern today.

The path from insecure attachment to risky or problematic drinking through alexithymia is consistent with the interpretation of such drinking as a manifestation of insecure adult attachment (De Rick et al. 2009; Flores, 2004). According to this view, alcohol intoxication can provide a "secure base" that was not reliably provided by a primary caregiver in childhood (Thorberg \& Lyvers, 2010). The perceived lack of a "secure base” in childhood may not only manifest as insecure attachment in adulthood, but also as alexithymia, because inadequate bonding to the primary caregiver is likely to interfere with normal development of emotional self-regulation and emotion-related cognitions (de Cock et al., 2017; Moore et al., 2009; Sprangler et al., 1996). For a highly alexithymic, heavydrinking adult, alcohol may thus serve to provide reliable comfort (anxiolysis) and stressrelief, as well as the "secure base" from which to experience and display emotions (via disinhibition) that was insufficiently enabled during childhood, and which current insecure attachments do not provide. 
The absence of any link between parental bonding experiences and ToM in the present study was, as noted earlier, inconsistent with predictions; however, the prediction of such a link was only tentative given the evidence that ToM development may be closely tied to language acquisition in children (Miller, 2006; Milligan, Astington, \& Dack, 2007) and thus may not necessarily reflect primary caregiver bonding experiences. For example, even without a strong maternal bond or "secure base," acquisition of language skills via schoolbased learning and requisite social interactions may still allow for normal development of ToM over time. Nevertheless, ToM was significantly negatively associated with alexithymia in the present study, consistent with the notion that the ability to recognize and describe emotional feelings in oneself is linked to the ability to do so for the emotions of others (Demers \& Koven, 2015; Lyvers, Kohlsdorf et al., 2017). The ToM index of RMET performance was a significant (though relatively weak) predictor of alexithymia in the final hierarchical regression model, independent of maternal dysfunction and insecure attachment. This finding may fit with the notion of a "primary" alexithymia (Freyberger, 1977) that mainly reflects genetic influences, in contrast to a "secondary" or acquired type that is more developmental in origin (and which is consistent in the present study with the path from maternal dysfunction in the path analysis). Further, there were both direct and indirect (via alexithymia) paths from ToM to risky drinking, consistent with the evidence of deficient ToM associated with AUD (Maurage et al., 2006; Onuoha et al., 2016). A plausible interpretation of the link to risky or problematic drinking is that poor ability to judge and appropriately respond to the emotional states of others may render an individual less inclined to seek social support when stressed, and instead turn to alcohol or other substances. Such an interpretation is in line with research in AUD client samples suggesting that those with alexithymia are less comfortable being intimate with a romantic partner and tend to be uncertain about whether they can depend on their partner (Thorberg et al., 2011a), as well as 
having a cold and avoidant interpersonal style (Spitzer et al., 2005).

The present study used a cross-sectional design, hence the findings can only be regarded as consistent with, but not direct evidence of, the temporal developmental sequences and causal relationships hypothesized in the proposed developmental model. If done properly, longitudinal research - an endeavor necessitating considerations of practicality, measurement, long-term follow-up and dropout issues - could provide support for such interpretations. The present study was intended to assess whether the associations among variables in an adult sample would be as hypothesized in the developmental model, a necessary step before resources of time and funding for an ambitious longitudinal project might be justified. Nevertheless, the present findings do suggest that alexithymia is likely to be associated with interpersonal and social difficulties which, if addressed successfully, might help reduce negative emotionality and alcohol-related risk in alexithymic clients, including those undergoing treatment for anxiety, mood or substance disorders. For example, anxious adult attachment could be targeted in therapy with the goal of establishing "earned adult attachment security” by rewriting historical working models of insecure childhood experiences (see McCarthy, Moller, \& Fouladi, 2001; Thorberg et al., 2011a). Further, based on the clinical experience of one of the present authors, group therapy can help improve alexithymic clients’ awareness of feelings through affect mirroring exercises and social learning. Evidence additionally suggests that cognitive behavioral therapy (CBT) can be effective in addressing alexithymia, as a previous study found reductions in alexithymia scores across a 12-week treatment period among alcohol-dependent clients (Thorberg et al., 2016b). Given that CBT is skills based, it may be especially useful in this context due to the alexithymic individual's externally oriented thinking style and focus on action rather than introspection. Finally, as the link between ToM and alcohol-related risk in the present sample showed an indirect effect of alexithymia, a focus on improving alexithymic individuals' 
understanding of others' intentions and emotions (see Onuoha et al., 2015) offers another possible approach to facilitate interpersonal functioning and reduce alcohol-related risk.

In conclusion, this is the first study to present a developmental model of alexithymia in relation to alcohol-related risk, integrating both early and adult Attachment Theory to suggest underlying mechanisms. Given that heritability estimates for alexithymia are low, developmental factors are likely to be central to the expression of this trait in many cases. As the current study used a cross-sectional approach, its findings cannot be interpreted as indicative of temporal or causal relationships among variables. Nevertheless the present findings are consistent with the hypothesis that dysfunctional maternal bonding in childhood may lead to insecure adult attachment and alexithymia, with the latter increasing vulnerability to alcoholrelated problems. Alexithymia is reportedly associated with the primary drinking motive of drinking to cope with stress or other negative affect (Lyvers, Coundouris, Edwards, \& Thorberg, 2018), as well as with alcohol expectancies of intensified affect (Thorberg et al., 2016a); such reports suggest that alexithymic drinkers seek both anxiolytic and disinhibiting effects of alcohol, possibly reflecting the lack of a foundational "secure base" in childhood and later in the context of insecure adult relationships. Further, alexithymia and deficient ToM appear to overlap in their relationships to alcohol-related risk. Longitudinal research will ultimately be required to support the proposed developmental pathways of alexithymia and the nature of its association with risky or problematic drinking as well as ToM deficits in both clinical and nonclinical samples. 


\section{References}

Ainsworth, M. D. S. (1991). Attachments and other affectional bonds across the life cycle. In C. M. Parkes, J. Stevenson-Hinde \& P. Marris (Eds.), Attachment across the life cycle (pp. 33-51). London: Routledge.

Asano, M., Esaki, K., Wakamatsu, A., Kitajima, T., Narita, T., Naitoh, H., Ozaki, N., \& Iwata, N. (2013). Maternal overprotection score of the Parental Bonding Instrument predicts the outcome of cognitive behaviour therapy by trainees for depression. Psychiatry and Clinical Neurosciences, 67, 340-344. doi:

\subsection{1/pcn.12054}

Babor, T.F., Higgins-Biddle, J.C., Saunders, J.B., \& Monteiro, M.G. (2001). The Alcohol Use Disorders Identification Test ( $2^{\text {nd }}$ ed.). World Health Organisation: Department of Mental Health and Substance Dependence.

Bagby, R. M., Parker, J. D. A., \& Taylor, G. J. (1994). The twenty-item Toronto Alexithymia Scale-I. Item selection and cross-validation of the factor structure. Journal of Psychosomatic Research, 38, 23-32. doi: 10.1016/00223999(94)90005-1

Bagby, R., Taylor, G., \& Parker, J. (1994). The twenty-item Toronto Alexithymia scale-II. Convergent, discriminant, and concurrent validity. Journal of Psychosomatic Research, 38, 33-40. doi: 10.1016/0022- 3999(94)90006-x

Baldwin, M.W., Carrell, S.E., \& Lopez, D.F. (1990). Priming relationship schemas: My advisor and the pope are watching me from the back of my mind. Journal of Experimental Social Psychology, 26, 435-454. doi: 10.1016/0022-1031(90)90068-W

Baron-Cohen, S., Wheelwright, S., Hill, J., Raste, Y., \& Plumb, I. (2001). The 
“'Reading the Mind in the Eyes”’ test revised version: A study with normal adults, and adults with Asperger syndrome or high-functioning Autism. Journal of Child Psychology and Psychiatry, 42, 241 - 251. doi: $10.1017 /$ S0021963001006643

Beadle, J.N., Paradiso, S., Salerno, A. \& McCormick, L.M. (2013). Alexithymia, emotional empathy, and self-regulation in anorexia nervosa. Annals of Clinical Psychology, 1, 107-120. doi: 10.1186/2050-2974-1-21

Blunch, N.J. (2008). Introduction to structural equation modelling using SPSS and Amos. London, UK: SAGE Publications.

Bowlby, J. (1958). The nature of the child's tie to his mother. International Journal of Psychoanalysis, 34, 1-23. doi: 10.1017/S0007087411000318

Bowlby, J., \& King, P. (2004). Fifty Years of Attachment Theory. London, UK: Karnac Books.

Brewer, R., Cook, R., \& Bird, G. (2016). Alexithymia: A general deficit of interoception. Royal Society Open Science, 3, 150664. doi: 10.1098/rsos.150664

Bruce, G., Curren, C., \& Williams, L. (2012). Alexithymia and alcohol consumption: The mediation effects of drinking motives. Addictive Behaviors, 37, 350-352. doi: 10.1016/j.addbeh.2011.11.024

Collins, N. L., \& Reed, S. J. (1990). Adult attachment, working models, and relationship quality in dating couples. Journal of Personality and Social Psychology, 58, 644-663. doi: 0.1037/0022-3514.58.4.644

Collins, N.L. (1996). Working models of attachment: Implications for explanation, emotion, and behavior. Journal of Personality and Social Psychology, 71, 810-832. doi: 10.1037/0022-3514.71.4.810 
Cruise, K.E., \& Becerra, R. (2018). Alexithymia and problematic alcohol use: A critical review. Addictive Behaviors, 77, 232-246. doi: 10.106/addbeh.2017.09.025

de Cock, E.S.A., Henrichs, J., Klimstra, T.A., Maas, A.J.B.M., Vreeswijk, C.M.J.M., Meeus, W.H.J., \& van Bakel., H.J.A. (2017). Longitudinal associations between parental bonding, parenting stress, and executive functioning in toddlerhood. Journal of Child and Family Studies, 26, 1723-1733. doi: 10.1007/s10826-0170679-7

Demers, L.A., \& Koven, N.S. (2015). The relation of alexithymic traits to affective theory of mind. American Journal of Psychology, 128, 31-42. URL: www.jstor.org/stable/10.546/amerjpsyc.128.1.0031

De Rick, A., Vanheule, S., \& Verhaeghe, P. (2009). Alcohol addiction and the attachment system: An empirical study of attachment style, alexithymia, and psychiatric disorders in alcoholic inpatients. Substance Use and Misuse, 44, 99 - 114. doi: $10.1080 / 10826080802525744$.

Edel, M.A., Edel, S., Kruger, M., Assion, H.J., \& Juckel, G. (2015). Attachment, recalled parental rearing, and ADHD symptoms predict emotion processing and alexithymia in adults with ADHD. Annals of General Psychiatry, 14, 2 - 9. doi: 10.1186/s12991-015- 0082-y

Faul, F., Erdfelder, E., Buchner, A., \& Lang, A.G. (2009). Statistical power analyses using G*Power 3.1: Tests for correlation and regression analyses. Behavior Research Methods, 41, 1149-1160. doi: 10.3758/BRM.41.4.1149

Flores, J.P. (2004). Addiction as an attachment disorder. Maryland, MD: Jason Aronson. Fraley, R.C., Hudson, N.W., Heffernan, M.E., \& Segal, N. (2015). Are adult attachment styles categorical or dimensional? A taxometric analysis of general and relationship-specific attachment orientations. Journal of Personality \& Social 
Psychology, 109, 354-368. doi: 10.1037/pspp0000027

Freyberger, H. (1977). Supportive psychotherapeutic techniques in primary and secondary alexithymia. Psychotherapy and Psychosomatics, 28, 337-345. doi:

\section{$10.1159 / 000287080$}

Gil., F.P., Scheidt, C.E., Hoeger, D., \& Nickel, M. (2009). Relationship between attachment style, parental bonding and alexithymia in adults with somatoform disorders. International Journal of Psychiatry in Medicine, 38, 437-451. doi: 10.2190/PM.38.4.d

Higgins, E. T., Klein, R., \& Strauman, T. (1985). Self-concept discrepancy theory: A psychological model for distinguishing among different aspects of depression and anxiety. Social Cognition, 3, 51-76. doi:

\subsection{1/soco.1985.3.1.51}

Higgins, E. T., Klein, R., \& Strauman, T. (1987). Self-discrepancies: Distinguishing among self-states, self-state conflicts, and emotional vulnerabilities. New York City, NY: Wiley.

Jørgensen, M.M., Zachariae, R., Skytthe, A., \& Kyvik, K. (2007). Genetic and environmental factors in alexithymia: A population-based study of 8,785 Danish twin pairs. Psychotherapy and Psychosomatics, 76, 369-375. doi: $10.1159 / 000107565$

Kuntsche, E., Knibbe, R., Gmel, G., \& Engels, R. (2005). Why do young people drink? A review of drinking motives. Clinical Psychology Review, 25, 841-61. doi:10.1016/j.cpr.2005.06.002.

Lane, R.D., Hsu, C.H., Locke, D.E., Ritenbaugh, C., \& Stonnington, C.M. (2015). Role of theory of mind in emotional awareness and alexithymia: Implications for conceptualisation and measurement. Consciousness and Cognition, 33, 398 - 
405. doi: 10.1016/j.concog.2015.02.004

Lane, R.D., Sechrest, L., \& Riedel, R. (1998). Sociodemographic correlates of alexithymia. Comprehensive Psychiatry, 39, 377-385. doi: 1016/S0010-440X(98)90051-7

Lennartsson, A.K., Horwitz, E.B., Theorell, T., \& Ullen, F. (2017). Creative artistic achievement is related to lower levels of alexithymia. Creativity Research Journal, 29, 29-36. doi: 10.1080/10400419.2017.1263507

Levant, R. F., Hall, R. J., Williams, C. M., \& Hasan, N. T. (2009). Gender differences in alexithymia. Psychology of Men \& Masculinity, 10, 190-203. doi: 10.1037/a0015652

Lovibond, S. H., \& Lovibond, P. F. (1995). Manual for the Depression Anxiety Stress Scales. Sydney: Psychology Foundation.

Lyvers, M., Coundouris, S., Edwards, M.S., \& Thorberg, F.A. (2018). Personality, drinking motives and risky alcohol use: The role of internal drinking motives. Addiction Research \& Theory, 26, 114-122. doi: $10.1080 / 16066359.2017 .1333110$

Lyvers, M., Davis, S., Edwards, M.S., \& Thorberg, F.A. (2017). Alexithymia, fear of intimacy and attachment in young adults. Journal of Psychology \& the Behavioral Sciences, 3, 1-11. doi: 10.22492/ijpbs.3.2.01

Lyvers, M., Kohlsdorf S.M., Edwards, M.S., \& Thorberg, F.A. (2017). Alexithymia and mood: Recognition of emotion in self and others. American Journal of Psychology, 130, 83-92. doi: 10.5406/amerjpsyc.130.1.0083

Mattila, A.K., Salminen, J.K., Nummi, T., \& Joukamaa, M. (2006). Age is strongly associated with alexithymia in the general population. Journal of Psychosomatic Research, 61, 629-635. doi: 10.1016/j.jpsychores.2006.04.013 Maurage, P., Grynberg, D., Noel, X., Joassin, F., Hanak, C., Verbanck, P., . . P Philippot, 
P. (2011). The "Reading the Mind in the Eyes" test as a new way to explore

complex emotions decoding in alcohol dependence. Psychiatry Research, 190, 375-378. doi: 10.1016/j.psychres.2011.06.015

McCarthy, C. J., Moller, N. P., \& Fouladi, R. T. (2001). Continued attachment to parents: Its relationship to affect regulation and perceived stress among college students. Measurement and Evaluation in Counseling and Development, 33, 198-213.

Meyers, L. S., Gamst, G., \& Guarino, A. J. (2017). Applied multivariate research: Design and interpretation (3rd ed.). Thousand Oaks, CA: Sage Publications.

Miller, C. A. (2006). Developmental relationships between language and theory of mind. American Journal of Speech-Language Pathology, 15, 142-154. doi:10.1044/1058-0360(2006/014).

Milligan, K., Astington, J. W., \& Dack, L. A. (2007). Language and theory of mind: Meta-analysis of the relation between language ability and false-belief understanding. Child Development, 78, 622-646. doi:10.1111/j.14678624.2007.01018.x.

Montebarocci, O., Codispoti, M., Baldaro, B., \& Rossi, N. (2004). Adult attachment style and alexithymia. Personality and Individual Differences, 36, 499-507. doi: 10.1016/S0191- 8869(03)00110-7

Moore, G.A., Hill-Soderlund, A.L., Propper, C.B., Calkins, S.D., Mills-Koonce, W.R., Cox, M.J. (2009). Mother-infant vagal regulation in the face-to-face still-face paradigm is moderated by maternal sensitivity. Child Development, 80, 209223. doi: 10.1111/j.1467-8624.2008.01255.x

Mueller, R.O. (1996). Basic principles of structural equation modelling. New York City, NY: Springer-Verlag New York, Inc.

Nelson, C. A., Zeanah, C. H., Fox, N. A., Marshall, P. J., Smyke, A. T., and Guthrie, 
D. (2007). Cognitive recovery in socially deprived young children: The

Bucharest Early Intervention Project. Science, 58, 1937-2940. doi:

10.1126/science.1143921

Onuoha, R.C., Quintana, D.S., Lyvers, M., \& Guastella, A.J. (2016). A metaanalysis of theory of mind in alcohol use disorders. Alcohol and Alcoholism, 51, 410-415. doi: 10.1093/alcalc/agv137

Parker, G., Tupling, H., and Brown, L.B. (1979) A Parental Bonding Instrument. British Journal of Medical Psychology, 52, 1-10. doi: 10.1111/j.20448341.1979.tb02487.x

Pasini, A., Chiaie, D., Seripa, S., \& Ciani, N. (1992). Alexithymia as related to sex, age, and educational level: Results of the Toronto Alexithymia Scale in 417 normal subjects. Comprehensive Psychiatry, 33, 42-46. doi: 10.1016/0010440X(92)90078-5

Schumacker, R.R., Marcoulides, G.A. (1998). Interaction and nonlinear effects in structural equation modelling. Mahwah, NJ: Lawrence Erlbaum Associates.

Spitzer, C., Siebel-Jurges, U., Barnow, S., Grabe, H. J., \& Freyberger, H. J. (2005).

Alexithymia and interpersonal problems. Psychotherapy and Psychosomatics, 74, 240-246. doi: 10.1159/000085148

Sprangler, G., Fremmer-Bombik, E., \& Grossmann, K. (1996). Social and individual determinants of infant attachment security and disorganization. Infant Mental Health Journal, 17, 127-139. doi: 10.1002/(SICI)10970355(199622)17:2<127::AID-IMHJ3>3.0.CO;2-N

Taylor, G.J., \& Bagby, R.M. (2000). An overview of the alexithymia construct. In R. Baron, \& Parker J.D.A. (Eds.), Handbook of emotional intelligence (pp. 40-67). San Francisco: Jossey-Bass. 
Taylor, G.J., Bagby, R.M., Kushner, S.C., Benoit, D., \& Atkinson, L. (2014).

Alexithymia and adult attachment representations: Associations with the fivefactor model of personality and perceived relationship adjustment.

Comprehensive Psychiatry, 55, 1258-1268. doi:

10.1016/j.comppsych.2014.03.015

Thorberg, F.A., \& Lyvers, M. (2006). Attachment, fear of intimacy and differentiation of self among clients in substance disorder treatment facilities. Addictive Behaviors, 31, 732- 737. doi: 10.1016/j.addbeh.2005.05.050

Thorberg, F.A., \& Lyvers, M. (2010). Attachment in relation to affect regulation and interpersonal functioning among substance use disorder inpatients. Addiction Research \& Theory, 18, 464-478. doi: 10.3109/16066350903254783

Thorberg, F.A., Young, R.M., Lyvers, M., Sullivan, K.A., Hasking, P., London, E.D., Connor, J.P., \& Feeney, F.X. (2016a). Alexithymia in relation to alcohol expectancies in alcohol-dependent outpatients. Psychiatry Research, 236, 186188. doi: 10.1016/j.psychres.2016.01.016

Thorberg, F. A., Young, R. McD., Sullivan, K. A., Lyvers, M., Hurst, C., Tyssen, R.,....., \& Feeney, G.F.X. (2016b). A prospective mediational study on the stability of alexithymia among alcohol-dependent outpatients in Cognitive-Behavioral Therapy. Psychology of Addictive Behaviors, 30, 64-72. doi: 10.1037/adb0000135

Thorberg, F.A., Young, R.M., Sullivan, K.A., \& Lyvers, M. (2009). Alexithymia and alcohol use disorders: A critical review. Addictive Behaviors, 34, 237-245. doi:10.1016/j.addbeh.2008.10.016

Thorberg, F.A., Young, R.M., Sullivan, K.A., \& Lyvers, M. (2011). Parental bonding and alexithymia: A meta-analysis. European Psychiatry, 26, 187-193. doi:

10.1016/j.eurpsy.2010.09.010 
Thorberg, F. A., Young, R. M., Sullivan, K. A., Lyvers, M., Hurst, C., Connor, J. P., \& Feeney, G. F. X. (2011a). Attachment security and alexithymia in a heavy drinking population. Addiction Research \& Theory, 19, 566-570. doi: $10.3109 / 16066359.2011 .580065$

Thorberg, F. A., Young, R. M., Sullivan, K. A., Lyvers, M., Hurst, C. P., Connor, J. P., \& Feeney, G. F. (2011b). Alexithymia in alcohol dependent patients is partially mediated by alcohol expectancy. Drug and Alcohol Dependence, 116, 238-241. doi: 10.1016/j.drugalcdep.2010.11.015

Tronick, E. (2007). The neurobehavioral and social-emotional development of infants and children. New York City, NY: W.W. Norton \& Company.

Vanheule, S., Desmet, M., Meganck, R., \& Bogaerts, S. (2007). Alexithymia and interpersonal problems. Journal of Clinical Psychology, 63, 109-117. doi: 10.1002/jclp.20324

Zafiropoulou, M., Avagianou, P.A., \& Vassiliadou, S. (2014) Parental bonding and early maladaptive schemas. Journal of Psychological Abnormalities, 3, 110-115. doi: 10.4172/2329-9525.1000110 


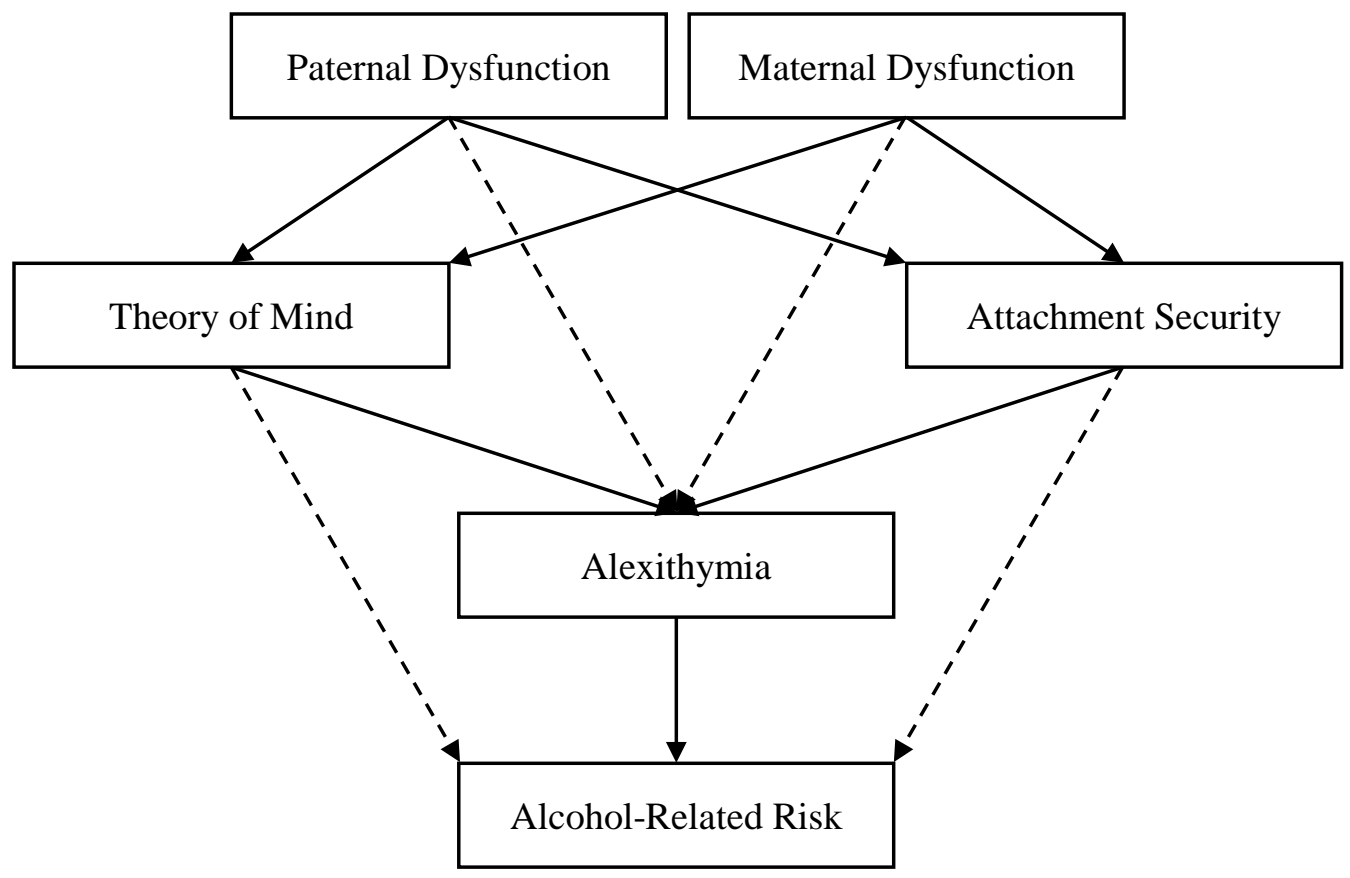

Figure 1. Representation of hypothesized developmental model of alcohol-related risk. 


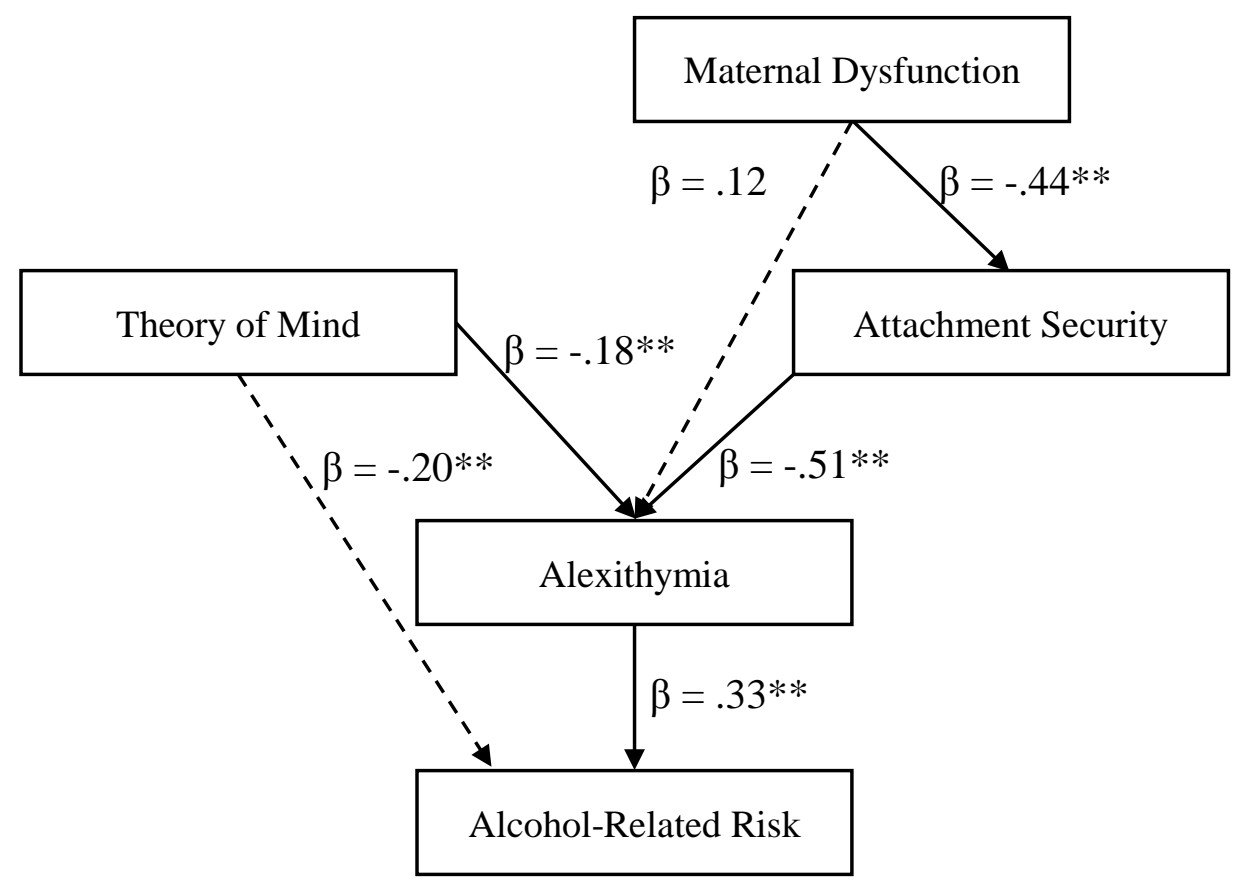

Figure 2. Refined model constructed post hoc by trimming non-significant paths.

${ }^{*} p<.05, * * p<.01$ 
Table 1

Means and standard deviations of study variables $(n=286)$.

Mean (SD)

TAS-20 Alexithymia

49.15 (13.15)

AUDIT Alcohol-Related Risk

9.17 (6.02)

PBI Maternal Care

$25.09(8.53)$

PBI Maternal Overprotection

$14.39(7.58)$

PBI Paternal Care

$21.77(9.11)$

PBI Paternal Overprotection

$12.09(7.76)$

Maternal Dysfunction

$25.15(13.86)$

Paternal Dysfunction

$26.48(14.38)$

AAS Close

AAS Depend

AAS Anxiety

Attachment Security

RMET Facial Recognition of Emotion

$24.62(6.35)$

DASS21 Negative Mood

$15.55(12.79)$

Note TAS-20 $=$ Toronto Alexithymia Scale; AUDIT = Alcohol Use

Disorders Identification Test; PBI = Parental Bonding Instrument;

AAS = Adult Attachment Scale; RMET = Reading the Mind in the

Eyes Test; DASS21 = Depression Anxiety Stress Scales 21 total score. 
Table 2

Pearson's bivariate correlations of continuous measures $(n=286)$.

\begin{tabular}{|c|c|c|c|c|c|c|c|c|c|c|c|c|c|}
\hline & TAS-20 & AUDIT & $\mathrm{MC}$ & MO & PC & $\mathrm{PO}$ & MatDys & PatDys & Close & Depend & Anxiety & Secure & RMET \\
\hline TAS-20 & - & & & & & & & & & & & & \\
\hline AUDIT & $.35^{* * *}$ & - & & & & & & & & & & & \\
\hline $\mathrm{MC}$ & $-.31 * * *$ & $-.14^{*}$ & - & & & & & & & & & & \\
\hline MO & $.29 * * *$ & $.12^{*}$ & $-.47 * * *$ & - & & & & & & & & & \\
\hline PC & $-.17 * *$ & -.08 & $.38 * * *$ & $-.27 * * *$ & - & & & & & & & & \\
\hline PO & $-.14^{*}$ & .06 & $-.25 * * *$ & $.41 * * *$ & $-.43 * * *$ & - & & & & & & & \\
\hline MatDys & $.35 * * *$ & $.15^{*}$ & $-.86 * * *$ & $.84 * * *$ & $-.36 * * *$ & $.37 * * *$ & - & & & & & & \\
\hline PatDys & $.17^{* *}$ & .08 & $-.38 * * *$ & $.39 * * *$ & $-.86^{* * *}$ & $.82 * * *$ & $.43^{* * *}$ & - & & & & & \\
\hline Close & $-.51 * * *$ & $-.12 *$ & $.33 * * *$ & $-.32 * * *$ & $.25^{* * *}$ & $-.20 * *$ & $-.37 * * *$ & $-.27 * * *$ & - & & & & \\
\hline Depend & $-.39 * * *$ & $-.12 *$ & $.33 * * *$ & $-.27 * * *$ & $.24 * * *$ & $-.18 * *$ & $-.34 * * *$ & $-.25 * * *$ & $.58 * * *$ & - & & & \\
\hline Anxiety & $.46 * * *$ & $.15^{*}$ & $-.31 * * *$ & $.32 * * *$ & $-.19 * *$ & $.16^{* *}$ & $.35 * * *$ & $.20 * *$ & $-.50 * * *$ & $-.61^{* * *}$ & - & & \\
\hline Secure & $-.52 * * *$ & $-.15^{* *}$ & $.38 * * *$ & $-.37 * * *$ & $.27 * * *$ & $-.20 * *$ & $-.42 * * *$ & $-.27 * * *$ & $.79 * * *$ & $.83 * * *$ & $-.87 * * *$ & - & \\
\hline RMET & $-.24 * * *$ & $-.22 * * *$ & .11 & -.06 & .03 & $-.17^{* *}$ & -.09 & -.11 & .10 & .07 & .04 & .08 & - \\
\hline DASS21 & $.51 * * *$ & $.24 * * *$ & $-.31^{* * *}$ & $.29 * * *$ & $-.24 * * *$ & $.24 * * *$ & $.35^{* * *}$ & $.28 * * *$ & $-.39 * * *$ & $-.40 * * *$ & $.45 * * *$ & $-.49 * * *$ & $-.13^{*}$ \\
\hline
\end{tabular}

Note. TAS-20 = Toronto Alexithymia Scale total; AUDIT = Alcohol Use Disorders Identification Test MC = Maternal Care; MO = Maternal Overprotect; PC = Paternal Care; PO = Paternal Overprotect; MatDys = Maternal Dysfunction; Pat.Dys = Paternal Dysfunction; Secure = Secure Attachment; RMET = Reading the Mind in the Eyes Test; DASS21 = Depression Anxiety Stress Scales 21 total score.

$* p<.05, * * p<.005, * * * p<.001$

This is the pre-peer reviewed version of the following article:

Lyvers, M., Mayer, K., Needham, K., \& Thorberg, F. A. (2019). Parental bonding, adult attachment, and theory of mind: A developmental model

of alexithymia and alcohol-related risk. Journal of Clinical Psychology, which has been published in final form at https://doi.org/10.1002/jclp.22772

This article may be used for non-commercial purposes in accordance with Wiley Terms and Conditions for Use of Self-Archived Versions 
Table 3

Hierarchical regression on alexithymia by theory of mind, parental bonding, and adult attachment, controlling for demographics.

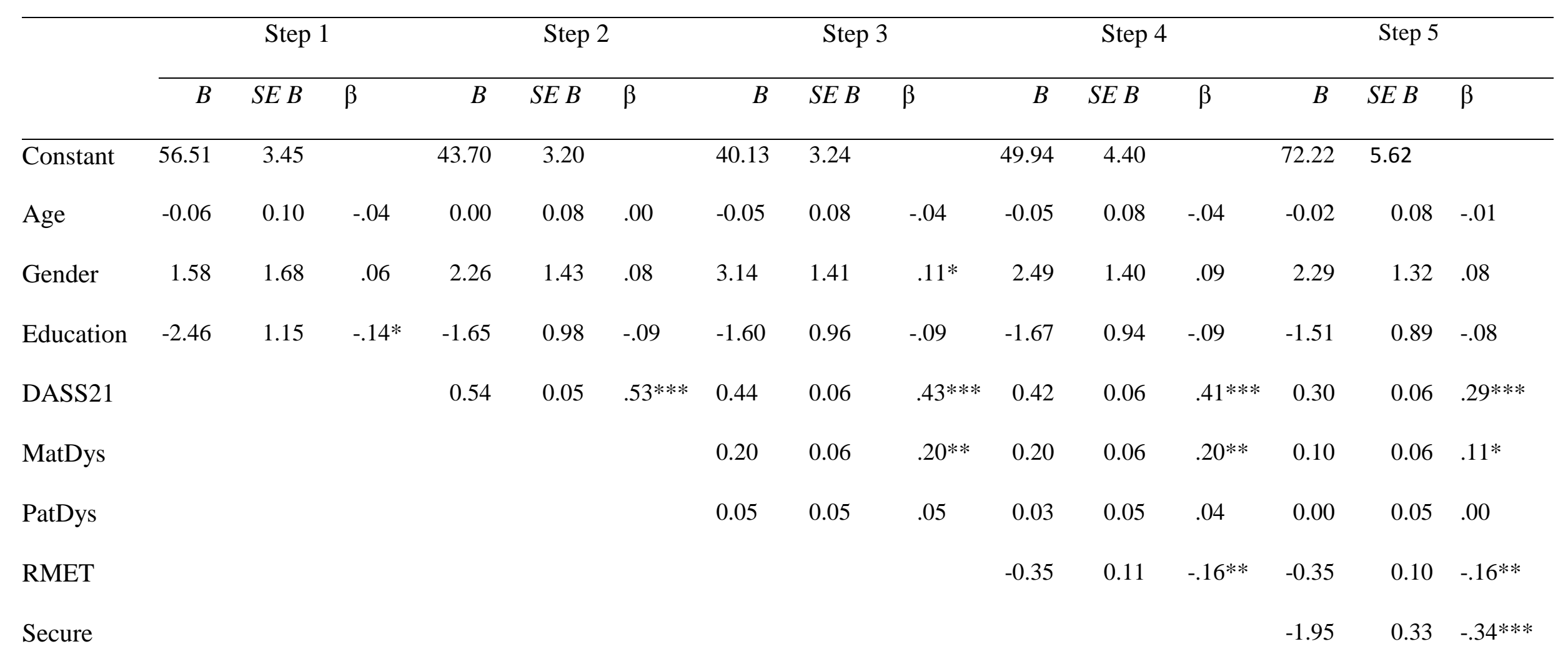

Note. $B=$ unstandardized coefficient; $S E B=$ standard error of $B ; \beta=$ standardized coefficient; DASS21 = Depression Anxiety Stress Scales 21;

MatDys = Maternal Dysfunction; PatDys = Paternal Dysfunction; RMET = Reading the Mind in the Eyes Test; Secure $=$ Secure Attachment

Style. ${ }^{*} p<.05, * * p<.005, * * * p<.001$ 
Table 4

Standardized regression coefficients, unstandardized regression coefficients, bootstrapped standard error of unstandardized coefficients, and associated 95\% confidence intervals for direct effects of the initial model

\begin{tabular}{lcccc}
\hline Path & $\beta$ & $B$ & SE $B$ & $95 \%$ CI for $B$ \\
\hline Paternal Dysfunction $\rightarrow$ Attachment & -.12 & -0.02 & 0.01 & {$[-0.04,0.00]$} \\
Paternal Dysfunction $\rightarrow$ Theory of Mind & -.10 & -0.04 & 0.03 & {$[-0.09,0.00]$} \\
Paternal Dysfunction $\rightarrow$ Alexithymia & -.01 & -0.01 & 0.05 & {$[-0.10,0.12]$} \\
Maternal Dysfunction $\rightarrow$ Attachment & -.38 & -0.07 & 0.01 & {$[-0.09,-0.05]$} \\
Maternal Dysfunction $\rightarrow$ Theory of Mind & -.06 & -0.03 & 0.03 & {$[-0.09,0.02]$} \\
Maternal Dysfunction $\rightarrow$ Alexithymia & .12 & 0.11 & 0.06 & {$[-0.01,0.24]$} \\
Attachment $\rightarrow$ Alexithymia & -.50 & -2.83 & 0.30 & {$[-3.44,-2.24]$} \\
Attachment $\rightarrow$ Alcohol Use & .06 & 0.16 & 0.16 & {$[-0.18,0.47]$} \\
Theory of Mind $\rightarrow$ Alexithymia & -.18 & -0.38 & 0.11 & {$[-0.58,-0.17]$} \\
Theory of Mind $\rightarrow$ Alcohol Use & -.20 & -0.20 & 0.07 & {$[-0.33,-0.07]$} \\
Alexithymia $\rightarrow$ Alcohol Use & .36 & 0.17 & 0.04 & {$[0.09,0.25]$} \\
\end{tabular}


Table 5

Standardized regression coefficients, unstandardized regression coefficients, bootstrapped standard error of unstandardized coefficients, and associated 95\% confidence intervals for indirect effects of the initial model

\begin{tabular}{lcccc}
\hline Path & $\beta$ & $B$ & SE B & 95\% CI for $B$ \\
\hline Paternal Dysfunction $\rightarrow$ Alexithymia (via Attachment) & .03 & 0.03 & 0.02 & {$[-0.02,0.07]$} \\
Paternal Dysfunction $\rightarrow$ Alexithymia (via Theory of Mind) & .00 & 0.01 & 0.01 & {$[-0.01,0.02]$} \\
Maternal Dysfunction $\rightarrow$ Alexithymia (via Attachment) & .10 & 0.10 & 0.03 & {$[0.05,0.16]$} \\
Maternal Dysfunction $\rightarrow$ Alexithymia (via Theory of Mind) & .00 & 0.00 & 0.01 & {$[-0.01,0.02]$} \\
Attachment $\rightarrow$ Alcohol Use (via Alexithymia) & -.18 & -0.48 & 0.13 & {$[-0.77,-0.25]$} \\
Theory of Mind $\rightarrow$ Alcohol Use (via Alexithymia) & -.07 & -0.06 & 0.03 & {$[-0.13,-0.02]$} \\
\hline
\end{tabular}

